\title{
Monitoring trans-Resveratrol in Grape Berry Skins During Ripening and in Corresponding Wines by HPLC
}

\author{
Elisabeta I. Geana ${ }^{1}$, Oana R. Dinca ${ }^{1}$, Roxana E. Ionete ${ }^{1}$, Victoria Artem ${ }^{2}$ and \\ Violeta C. Niculescu ${ }^{1 *}$ \\ ${ }^{1}$ National R\&D Institute for Cryogenics and Isotopic Technologies - ICIT Rm. Valcea, 4th Uzinei Street, \\ PO Raureni, Box 7, RO-240050 Rm. Valcea, Romania \\ ${ }^{2}$ Research Station for Viticulture and Oenology Murfatlar, RO-905100 Murfatlar, Romania \\ Received: June 10, 2014 \\ Accepted: January 15, 2015
}

\begin{abstract}
Summary
Trans-resveratrol (3,5,4'-trihydroxy-trans-stilbene) is naturally present in the skin of grapes and therefore is expected to occur in grape products. Recently, there has been a renewal of interest in wine as medical treatment for various disorders. In this study, berry skins of five red grape varieties were analysed at weekly intervals for trans-resveratrol production, during 2012 and 2013 harvest. The obtained wines were also evaluated. Quantification of trans-resveratrol in grape skin extracts and wines was carried out by high-performance liquid chromatography. Favourable viticultural climate during harvest in 2012 resulted in a higher content of trans-resveratrol. The highest trans-resveratrol content was in Pinot Noir and Feteasca Neagra grape varieties, both in berry skins and wines, while the lowest amounts were identified in Cabernet Sauvignon variety. We can conclude that there was a significant correlation between the content of trans-resveratrol in grape skins and that in the respective wine.
\end{abstract}

Key words: antioxidant activity, grape, wine, trans-resveratrol, HPLC

\section{Introduction}

Trans-resveratrol (3,5,4'-trihydroxy-trans-stilbene) is a naturally occurring stilbene phytoalexin present in many vegetables and in related foods, abundant in fresh grape skin and red wine; it is produced by plants in response to fungus infections or exposure to UV light (1). It has been demonstrated to produce a variety of actions. These effects include estrogenic, antioxidant (2), anti-inflammatory and anticancerogenic properties, and it may exert protective effect on the cardiovascular system (3).

In grape, stilbenes are considered to be located essentially in the skin and mainly in glycosylated form. These compounds were also reported to be present in grape seeds and grape stems (4). In wines, resveratrol may be present in two isomer forms, trans and cis, but only its trans isomer has been identified in Vitis vinifera grapes, the cis-resveratrol is formed from trans isomer during winemaking process due to the photochemical isomerization of trans-resveratrol (5-7).

Biosynthesis and accumulation of phenolic compounds, including trans-resveratrol, in grape berries depends on the climatic and geographical factors, cultural practices and the stage of ripeness $(7,8)$. Also, the concentration of trans-resveratrol in the skins of ripening grapes varies considerably, depending on the variety, and it was found to be negatively correlated with the developmental stage of berries (6). Extraction of resveratrol from grape skins during winemaking should be completed before or at the end of alcoholic fermentation.

The polyphenolic content in wine depends on several parameters, such as the grape variety (9), maceration $(10,11)$, yeast $(12)$ and other vinification conditions (13). Therefore, red wines contain much higher concentrations of trans-resveratrol than the rosé wines, while only trace 
amounts of such compound can be found in the white wines $(5,14,15)$. Also, in our previous works, we found higher amounts of phenolic compounds in red wines compared to white wines (16-18).

Various techniques have been used for the determination of trans-resveratrol in liquid samples: gas chromatography-mass spectrometry, GC-MS (19), capillary electrophoresis (20) or the most commonly utilised reversed phase high-performance liquid chromatography, RP-HPLC, either with UV detection $(21,22)$, fluorimetric detection (1) or with mass spectrometric detection (23); this compound can be easily determined in wines and other drinks by means of direct injection $(5,14)$.

Many studies have focused on the trans-resveratrol concentration in red wines (14,24-26), relatively few have examined the trans-resveratrol content in berry skin and several authors have studied the transference of stilbenes from grape to red wines $(6,27)$.

In order to perform the analysis of trans-resveratrol in grape berry skin, the used methods required consecutive extractions or sample derivatization prior to analysis and this is especially problematic considering that trans-resveratrol is an easily oxidizable and photosensitive compound (28). For this reason, the extraction processes must be performed with the samples protected as much as possible from the air and light (1).

Solvent extraction (29), ultrasonication $(30,31)$ and extraction with supercritical fluid (32) or pressurized liquid extraction (PLE) (1) are the most common techniques for the isolation of phenolic compounds. In extraction techniques, organic solvents are commonly used to recover phenolic compounds from plant tissues (33). Ethyl acetate, acetone, ethanol, methanol and methanol acidified by $0.1 \% \mathrm{HCl}$ are among the solvents used to extract stilbene compounds from grape skin (6). Solvent extraction with ethanol/water (80:20 \%, by volume) maintained at 60 ${ }^{\circ} \mathrm{C}$ for $30 \mathrm{~min}$ represents a very good extraction procedure (30), but the temperature or time condition may cause the degradation of solubilized resveratrol.

The variation of quality parameters or biologically active compounds depending on variety, harvest year or harvest date was proven in many vegetable products. For example, Piscopo et al. (34) studied the effect of harvest time on kernel quality of several almond varieties, while Wassner et al. (35) investigated the fatty acid composition in seeds of a natural population of Jatropha macrocarpa at different ripening stages. Variations of sterols (36), triglycerides (37), fatty alcohols (38) and wax (39) were studied in olive oil depending on variety $(36,37,39)$, harvest year $(37,39)$ or harvest date $(36,38)$. Changes in phenolic (8) or trans-resveratrol (40) content of berry skin of different red grape varieties during ripening were also investigated by Giuffré.

Thus, the main objective of this paper is to study the influence of variety, harvest date and harvest year on the trans-resveratrol content in grape berry skin. For that, five grape varieties of Vitis vinifera L.: Pinot Noir, Merlot, Cabernet Sauvignon, Feteasca Neagra and Mamaia cultivated in Murfatlar vineyard in Dobrogea wine-producing area located in the Southeast Romania were analysed for trans-resveratrol content during the last six weeks of techno- logical maturation (from August to September), in two harvest years (2012 and 2013), in order to define the moment of maximum accumulation of this antioxidant in relation to the moment when the grapes have the optimum chemical composition for obtaining wines with specific characteristics. In this respect, we have identified and quantified trans-resveratrol in grape skins of the studied Vitis vinifera varieties and resulting wines based on a liquid-liquid extraction method (LLE) followed by HPLC analysis with ultraviolet-visible photodiode array detector (PDA). The second objective of this work is to establish a relationship between the levels of trans-resveratrol in grape skin and those of the corresponding wines in both years.

\section{Materials and Methods}

\section{Reagents, standards and calibration}

All chemicals used (methanol, acetonitrile and glacial acetic acid (100\% p.a.)) were of analytical or HPLC grade and obtained from Merck (Darmstadt, Germany). Double-distilled and demineralised water produced by a Milli-Q Millipore system (Bedford, MA, USA) was used for preparation of the aqueous solutions.

The trans-resveratrol standard (99\% GC) was purchased from Sigma-Aldrich (Steinheim, Germany) and ethanol $96 \%$ was obtained from Merck. A stock solution of $100 \mathrm{mg} / \mathrm{L}$ of trans-resveratrol was prepared in a $12 \%$ hydroalcoholic solution. The solid standard was initially dissolved in a minimum volume of ethanol, before the addition of water, in order to guarantee a complete dissolution. Immediately prior to analysis, a set of standards covering the range from 0.5 to $25 \mathrm{mg} / \mathrm{L}$ and control sample were prepared from the stock solution, diluted in a $12 \%$ ethanolic solution. Special care was taken in relation to the degradation of the standard solutions, keeping them protected from air and light exposure to avoid oxidative degradation and isomerization of the trans-resveratrol to the cis one.

\section{Sampling}

In this study, 70 samples of five red grape varieties (Vitis vinifera L.): Pinot Noir, Merlot, Cabernet Sauvignon, Feteasca Neagra and Mamaia cultivated in Murfatlar vineyard (Romania) were investigated. The representative samples were harvested weekly, all varieties on the same day, except for the last sampling day, starting with veraison, followed by intermediate and ripening stage, from August to September, in two years, 2012 and 2013 (7 representative grape samples of each variety, 35 representative grape samples for each year, in total). Last sampling day depended on grape variety and represented the day when each grape variety reached the technological maturity characterised by the accumulation of large amounts of sugars, reduction of excessive acidity of grapes and also considerable values of phenolic compounds, in order to obtain quality wines. In one of our previous studies (41), we established that the optimum time for full technological maturity of Cabernet Sauvignon and Feteasca Neagra grapes was reached on 12 September, of Pinot Noir on 13 September, of Mamaia on 14 September and Merlot on 17 September. 
To avoid possible errors, sampling was done from 20 marked hubs with medium production, placed at different points, covering the unevenness of the ground, exposition and slope. Each sample consisted of small portions of bunches from the base, middle and top of the grape bunch, which were located at the base, middle and top of the vine. Healthy grape berries were snipped from the clusters, the skin from 50 healthy berries, randomly selected, was manually separated from pulp and seeds, weighed then frozen and stored at $-20{ }^{\circ} \mathrm{C}$ until analysis (at the end of harvest, for each year).

The studied red grape varieties are deposited in the ampelographic collection of the Murfatlar Research and Development Station for Viticulture and Oenology, Romania. They were planted in 2001, on the 1-2 \% slope having an east-west exposure; the soil type is calcareous black earth with loamy texture, the culture system is semi-high with $70 \mathrm{~cm}$ strain, bilateral cordon with cutting rings of fruit, with $2.4 \mathrm{~m} \times 1.2 \mathrm{~m}$ planting distance and a density of 3472 vines per ha. The vines were treated according to the warnings and climatic conditions in the studied years, aiming to maintain healthy foliage, to support production and ensure good differentiation of the buds for next year's harvest. In 2012 and 2013, seven treatments were performed using only active substances permitted in the internationally integrated control of pests and diseases of vines.

All wine samples were produced on a small scale from the corresponding ripe grapes (batches of 150-200 $\mathrm{kg}$ ) in the Laboratory of Processing Technology of Grape and Wine Chemistry at Microvinification Department of Research Station for Viticulture and Oenology Murfatlar (SCDVV Murfatlar, Romania), applying traditional technology of obtaining quality dry red wines, without using any selected yeasts, nutrients or enzymes (42). After the end of fermentation, the wine was stored and aged in stainless steel containers for a period of 6 months, followed by the application of specific operations: fill-up of the wine recipients, raking, sulphitation and resulphitation, as appropriate. Then two bottle samples $(750 \mathrm{~mL})$ of each investigated wine were obtained directly from the Murfatlar vineyard and analysed. Once opened, wine samples were analysed immediately after filtration through 30-mm Teflon syringe filters, $0.45 \mu \mathrm{m}$ (Thermo Scientific, Rockwood, TN, USA). All wine samples were analysed in two replications.

\section{Extraction of trans-resveratrol from grape skins}

In this paper, extraction of trans-resveratrol from grape skins was carried out according to the procedure proposed by Tardea (43). Frozen grape skins were partially thawed and grinded for $15 \mathrm{~min}$ (protected from light) with $2 \mathrm{~g}$ of quartz sand and $10 \mathrm{~mL}$ of methanol for each gram of grape skins. The extracts were centrifuged for 15 min at $17226 \times g$ with a universal centrifuge, Hermler 326 (HERMLE Labortechnik GmbH, Wehingen, Germany) with the air flow that keeps the samples cool, followed by washing of precipitates with methanol. The combined extracts were evaporated under reduced pressure at $40{ }^{\circ} \mathrm{C}$ using a rotary evaporator, and the solid residue was dissolved in $100 \mathrm{~mL}$ of ethyl acetate and $100 \mathrm{~mL}$ of a $3 \%$ sodium bicarbonate solution. Organic extracts were washed three times with 50-mL aliquots of Milli-Q water (Millipore), dried over anhydrous sodium sulphate and evaporated to dryness, under reduced pressure, at $40{ }^{\circ} \mathrm{C}$. The residues were dissolved in $2.5 \mathrm{~mL}$ of absolute ethanol and these solutions were finally injected into HPLC system after filtering through a $0.45-\mu \mathrm{m}$ Teflon filters (Thermo Scientific). During sample preparation, extracts were constantly protected from light using light-proof containers to avoid photochemical isomerization of trans-resveratrol to the cis form. Recovery was determined for the overall assay by adding known amounts of trans-resveratrol to the original concentration of the analysed samples and the obtained values were between 85 and $93 \%$.

\section{HPLC analysis}

Chromatographic analysis was carried out with a Thermo Finnigan Surveyor Plus chromatograph (Thermo Fisher Scientific Inc., Waltham, MA, USA) equipped with a photodiode array detector, Surveyor autosampler and Surveyor LC Pump (quaternary gradient). Data analysis was done using the ChromQuest ${ }^{\mathrm{TM}}$ Chromatography Workstation (Thermo Fisher Scientific Inc.). HPLC determinations were achieved by the method optimised previously (44). The analytical column Aquasil C18, 250 $\mathrm{mm} \times 4.6 \mathrm{~mm}$ and $5 \mu \mathrm{m}$ particle size (Thermo Fisher Scientific Inc.) was used for separation. Optimised chromatographic conditions were as follows: mobile phase mixed of water/acetonitrile/acetic acid at 70:29.9:0.1 flowed through the system at the rate of $1 \mathrm{~mL} / \mathrm{min}$, injection volume was $20 \mu \mathrm{L}$, and detection was set at $310 \mathrm{~nm}$.

Quantification was done using a ChromQuest v. 4.2 chromatographic software (Thermo Fisher Scientific Inc.) and it was based on the peak area and an external standard method. All analyses were carried out in duplicate, at ambient temperature. Blank solution and control samples were analysed for each set of ten samples in order to monitor the performance related to variable factors or random error. To evaluate the efficiency of the HPLC procedure, samples were also spiked with the trans-resveratrol standard.

\section{Statistical analysis}

The analysis of variance (ANOVA) was performed using Microsoft Excel 2010 (Microsoft Corporation, Redmond, WA, USA) and XLSTAT v. 15.5.03.3707 (Addinsoft, Paris, France). The Duncan's test was used to discriminate the different varieties $(\mathrm{p} \leq 0.05)$. For the ANOVA analysis, the factors taken into consideration in this study were the harvest period, variety, harvest year and the interaction between these factors.

\section{Results and Discussion}

\section{Identification of trans-resveratrol in grape skins and red wines}

Typical HPLC chromatograms of grape skins and red wines are presented in Figs. 1 and 2, respectively. Trans-resveratrol was identified by the comparison of retention times and UV spectra with commercial trans-resveratrol standard. To confirm trans-resveratrol peak identity among 


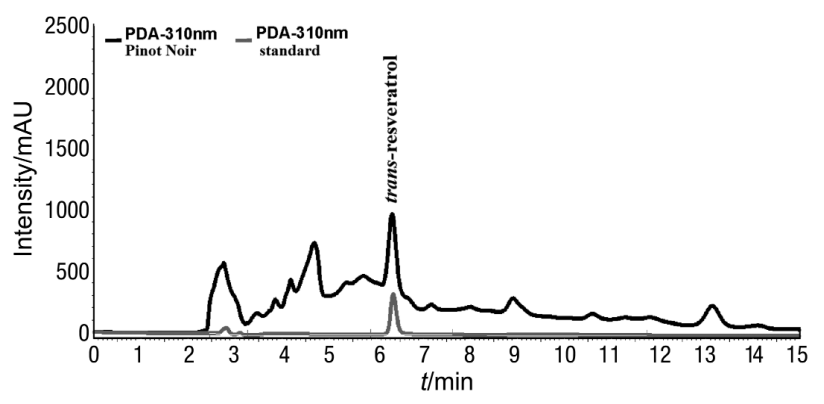

Fig. 1. HPLC chromatogram of grape skin (Vitis vinifera, Pinot Noir) extract and standard

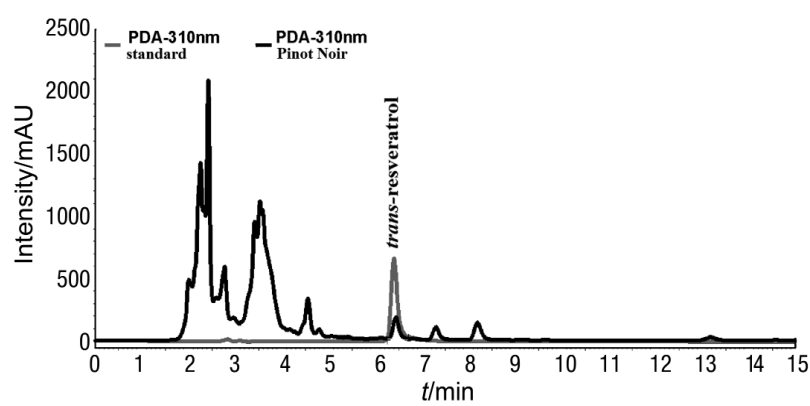

Fig. 2. HPLC chromatogram of red wine (Vitis vinifera, Pinot Noir) and standard

possible interfering peaks in its vicinity, the technique of standard addition to the sample was applied. To ensure that no coeluting or comigrating impurity contribute to the peak response, the peak purity was verified and the obtained values were satisfactory.

\section{Variation of trans-resveratrol content during grape ripening}

The content of trans-resveratrol during ripening of five red grape varieties, Feteasca Neagra, Pinot Noir, Merlot, Cabernet Sauvignon and Mamaia, in two different harvest years is presented in Table 1. The values in the same row followed by the same lowercase letter were not significantly different according to the Duncan's multiple range test at $\mathrm{p} \leq 0.05$ for the sampling period. Mean values in the same column with different uppercase letters differ significantly $(\mathrm{p} \leq 0.05)$ depending on the variety and harvest year.

The ANOVA results indicate that trans-resveratrol content in the berry skin was significantly affected by the variety or harvest year and each variety had a different ripening trend (Table 1). Trans-resveratrol was highly significantly different $(\mathrm{p} \leq 0.05)$ in Feteasca Neagra variety in 2012 harvest and Pinot Noir variety in 2013 harvest during the seven harvest dates. In all remaining varieties, trans-resveratrol showed partial or not significant differences. Evaluating the data from Table 1, column by column, we can say that differences are significant for each harvest date $(\mathrm{p} \leq 0.05)$, mainly for the last, when we can differentiate almost each variety and harvest year (except Feteasca Neagra, Pinot Noir and Cabernet Sauvignon varieties in 2013 harvest).

High level of trans-resveratrol was identified in the grape skin of Pinot Noir variety with values ranging from 0.92 to $29.5 \mathrm{mg} / \mathrm{kg}$ in 2012, and from 0.25 to $4.0 \mathrm{mg} / \mathrm{kg}$ in 2013. It is followed by Feteasca Neagra with variations between 1.1 and $18.7 \mathrm{mg} / \mathrm{kg}$ in 2012, and between 0.81 and $3.03 \mathrm{mg} / \mathrm{kg}$ in 2013, and Merlot with values from 1.4 to 5.3 $\mathrm{mg} / \mathrm{kg}$ in 2012, and from 0.15 to $4.76 \mathrm{mg} / \mathrm{kg}$ in 2013. Trans-resveratrol in grape skins of Cabernet Sauvignon and Mamaia varieties was relatively lower with values between 0.8 and $1.7 \mathrm{mg} / \mathrm{kg}$ in 2012, and 0.13 and $2.77 \mathrm{mg} / \mathrm{kg}$ in 2013 in Cabernet Sauvignon, and 0.50-9.28 mg/kg in 2012 and $0.03-0.37 \mathrm{mg} / \mathrm{kg}$ in 2013 in Mamaia.

An increase in trans-resveratrol content with a maximum accumulation on the harvest day was observed in Feteasca Neagra and Merlot grape skins. Its increase was also observed in Pinot Noir grape variety until the fifth or sixth sampling day, followed by a decrease, so it can be concluded that in this variety a higher degree of grape ripeness leads to lower trans-resveratrol content.

Table 1. Change in the trans-resveratrol content (in $\mathrm{mg} / \mathrm{kg}$ ) in berry skins during grape ripening

\begin{tabular}{|c|c|c|c|c|c|c|c|}
\hline \multirow{2}{*}{ Variety } & \multicolumn{7}{|c|}{ Sampling date } \\
\hline & Aug. 6 & Aug. 13 & Aug. 20 & Aug. 27 & Sept. 3 & Sept. 10 & Harvest \\
\hline Feteasca Neagra 2012 & $(1.1 \pm 0.2)^{\mathrm{fC}}$ & $(2.0 \pm 0.1)^{\mathrm{eBC}}$ & $(5.1 \pm 0.1)^{\mathrm{dB}}$ & $(10.3 \pm 0.5)^{\mathrm{bA}}$ & $(6.4 \pm 0.3)^{\mathrm{cB}}$ & $(2.3 \pm 0.2)^{\mathrm{eD}}$ & $(18.7 \pm 0.2)^{\mathrm{aA}}$ \\
\hline Feteasca Neagra 2013 & $(0.35 \pm 0.09)^{\mathrm{cdDE}}$ & $(0.21 \pm 0.06)^{\mathrm{dF}}$ & $(0.81 \pm 0.09)^{\mathrm{bE}}$ & $(0.19 \pm 0.03)^{\mathrm{dFG}}$ & $(2.7 \pm 0.1)^{\mathrm{aCD}}$ & $(0.6 \pm 0.2)^{\mathrm{bcEF}}$ & $(3.03 \pm 0.07)^{\mathrm{aF}}$ \\
\hline Pinot Noir 2012 & $(2.9 \pm 0.1)^{\mathrm{deA}}$ & $(2.65 \pm 0.09)^{\mathrm{deA}}$ & $(6.1 \pm 0.13)^{\mathrm{cdA}}$ & $(0.92 \pm 0.04)^{\mathrm{eCDE}}$ & $(29.5 \pm 3.0)^{\mathrm{aA}}$ & $(8.5 \pm 0.3)^{\mathrm{cA}}$ & $(13.0 \pm 0.4)^{\mathrm{bB}}$ \\
\hline Pinot Noir 2013 & $(0.25 \pm 0.07)^{\mathrm{fDE}}$ & $(1.3 \pm 0.1)^{\mathrm{eDE}}$ & $(1.1 \pm 0.1)^{\mathrm{eE}}$ & $(1.9 \pm 0.1)^{\mathrm{dB}}$ & $(3.3 \pm 0.1)^{\mathrm{bBCD}}$ & $(4.0 \pm 0.1)^{\mathrm{aBC}}$ & $(2.4 \pm 0.1)^{\mathrm{CG}}$ \\
\hline Merlot 2012 & $(1.6 \pm 0.1)^{\mathrm{dB}}$ & $(1.9 \pm 0.2)^{\mathrm{dBC}}$ & $(2.5 \pm 0.2)^{\mathrm{cC}}$ & $(1.4 \pm 0.2)^{\mathrm{dBCD}}$ & $(4.0 \pm 0.2)^{\mathrm{bBC}}$ & $(4.4 \pm 0.2)^{\mathrm{bB}}$ & $(5.3 \pm 0.1)^{\mathrm{aD}}$ \\
\hline Merlot 2013 & $(0.19 \pm 0.03)^{\mathrm{eE}}$ & $(2.1 \pm 0.1)^{\mathrm{bB}}$ & $(0.67 \pm 0.04)^{\mathrm{dE}}$ & $(1.44 \pm 0.07)^{\mathrm{cBC}}$ & $(1.30 \pm 0.05)^{\mathrm{cCD}}$ & $(0.15 \pm 0.04)^{\mathrm{eF}}$ & $(4.76 \pm 0.09)^{\mathrm{aE}}$ \\
\hline Mamaia 2012 & $(0.6 \pm 0.1)^{\mathrm{eD}}$ & $(1.64 \pm 0.08)^{\mathrm{cCD}}$ & $(0.8 \pm 0.2)^{\mathrm{deE}}$ & $(0.50 \pm 0.08)^{\mathrm{eEFG}}$ & $(1.1 \pm 0.1)^{\mathrm{dCD}}$ & $(3.9 \pm 0.1)^{\mathrm{bC}}$ & $(9.3 \pm 0.2)^{\mathrm{aC}}$ \\
\hline Mamaia 2013 & $(0.09 \pm 0.02)^{\mathrm{cE}}$ & $(0.37 \pm 0.06)^{\mathrm{aF}}$ & $(0.16 \pm 0.05)^{\mathrm{bcF}}$ & $(0.04 \pm 0.01)^{\mathrm{cG}}$ & $(0.24 \pm 0.05)^{\mathrm{abD}}$ & $(0.34 \pm 0.04)^{\mathrm{aEF}}$ & $(0.03 \pm 0.02)^{\mathrm{cI}}$ \\
\hline Cabernet Sauvignon 2012 & $(1.7 \pm 0.2)^{\mathrm{aB}}$ & $(1.2 \pm 0.2)^{\mathrm{abE}}$ & $(1.6 \pm 0.3)^{\mathrm{aD}}$ & $(0.8 \pm 0.2)^{\mathrm{bDEF}}$ & $(0.8 \pm 0.2)^{\mathrm{bCD}}$ & $(0.8 \pm 0.2)^{\mathrm{a}} \mathrm{b}^{\mathrm{E}}$ & $(1.1 \pm 0.2)^{\mathrm{abH}}$ \\
\hline Cabernet Sauvignon 2013 & $(0.15 \pm 0.04)^{\mathrm{dE}}$ & $(0.24 \pm 0.03)^{\mathrm{cdF}}$ & $(0.13 \pm 0.03)^{\mathrm{dF}}$ & $(0.36 \pm 0.04)^{\mathrm{cEFG}}$ & $(0.62 \pm 0.04)^{\mathrm{bCD}}$ & $(0.67 \pm 0.06)^{\mathrm{bEF}}$ & $(2.77 \pm 0.08)^{\mathrm{aFG}}$ \\
\hline
\end{tabular}

The values represent the mean of the results obtained for the two replicate analyses \pm standard deviation. The letters represent the different groups from the interactions between the studied factors (variety and harvest year: uppercase letters in the column, and harvest period: lowercase letters in the row) according to the Duncan's multiple range test at $\mathrm{p} \leq 0.05$ 
In Mamaia variety, there is a big difference between the trans-resveratrol content in the grape skins in the two years of harvest due to the climatic conditions, which were favourable in 2012. Also, in Mamaia variety, during 2012 harvest, the trans-resveratrol content in grape skins was higher at the end of the ripening, while in 2013 harvest, the trans-resveratrol content greatly decreased on harvest day and a possible explanation could be that it rained on that day. In Cabernet Sauvignon grape skins, the moment of maximum accumulation of trans-resveratrol was at the end of ripening period. Also, according to various studies $(41,45)$, the phenolic maturity of Cabernet Sauvignon was achieved at the end of ripening period.

Similar values of trans-resveratrol in skins were reported by Giuffré (40) in red grape varieties, other than those presented in this study but in their case trans-resveratrol content decreased during ripening.

\section{Trans-resveratrol content in red wines}

Five red wine varieties from 2012 and 2013 harvests were analysed in order to establish trans-resveratrol content. In 2012, the amount of trans-resveratrol ranged between 0.32 and $3.26 \mathrm{mg} / \mathrm{L}$, with the highest amount in Pinot Noir red wine variety, followed by Merlot, Feteasca Neagra and Mamaia. In 2013, the amount of trans-resveratrol ranged between 0.3 and $2.12 \mathrm{mg} / \mathrm{L}$, with the highest values in Merlot, followed by Pinot Noir, Feteasca Neagra and Mamaia varieties. The lowest trans-resveratrol content was identified in Cabernet Sauvignon wine variety in both harvest years (Fig. 3).

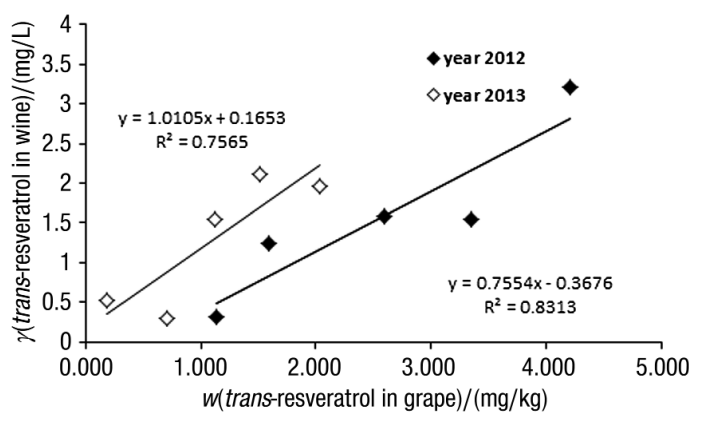

Fig. 3. Linear correlation between the content of trans-resveratrol in grape skins and corresponding red wines

In vinification, maceration with skins and seeds during fermentation is responsible for higher resveratrol concentrations in red wine in comparison with the white wine (46). In one of our earlier studies regarding polyphenolic composition of Romanian wine (16) including trans-resveratrol content, we observed a variation in the phenolic content amongst white and red wines, and also amongst wines made from grapes of different geographical origin (Muntenia, Dobrogea and Moldavia). Red wines were found to have higher concentrations of trans-resveratrol (1.03-5.81 mg/L) compared with those produced from white varieties $(0.37-0.95 \mathrm{mg} / \mathrm{L})(16)$, which is due to the maceration with skins and seeds during fermentation in winemaking process of the red wine $(5,46)$. Trans-resveratrol concentration in red wines from Dobrogea region ranged from 1.03 to $5.26 \mathrm{mg} / \mathrm{L}$, while in the red wine from Muntenia region it ranged from 2.03 to 2.65 $\mathrm{mg} / \mathrm{L}$, and from 1.64 to $5.81 \mathrm{mg} / \mathrm{L}$ in Moldavia region. Red Merlot wines appeared to contain significant amounts of trans-resveratrol (16). Among red wine varieties investigated in a previous study, the Merlot had higher amounts of trans-resveratrol compared to the other varieties (Cabernet Sauvignon, Feteasca Neagra and Pinot Noir) (16).

Also, the results reported in this paper were in concordance with the literature from other countries. Cvejic et al. (15), investigating Serbian commercial wines, reported $0.11 \mathrm{mg} / \mathrm{L}$ of trans-resveratrol in Merlot and values ranging from 0.18 to $1.69 \mathrm{mg} / \mathrm{L}$ in Cabernet Sauvignon. In Hungarian red wines, trans-resveratrol concentration varied from 1.18 to $9.34 \mathrm{mg} / \mathrm{L}$ in Cabernet Sauvignon, while values from 2.21 to $14.32 \mathrm{mg} / \mathrm{L}$ and 2.83 to $3.73 \mathrm{mg} / \mathrm{L}$ were reported in Merlot and Pinot Noir, respectively (47).

\section{Correlation between the trans-resveratrol levels in grape skins and in corresponding wines}

The level of trans-resveratrol was considered in order to establish the relationship between the trans-resveratrol content of grape skins and that of the corresponding wines in two consecutive harvest years. Correlation tests were performed and linear correlation coefficients $\left(R^{2}\right)$ are presented in Fig. 3.

Better correlation between the trans-resveratrol content in grape skins and corresponding wines was observed in 2012 harvest, with a correlation coefficient of 0.8813 , compared with a value of 0.7565 for 2013 harvest. This indicates that the level of resveratrol in grape skins might be used as an indicator to predict the level of this compound in the corresponding red wines.

Pinot Noir, Merlot and Feteasca Neagra red wines have higher amounts of trans-resveratrol, while Cabernet Sauvignon variety contains its relatively lower amount in both grape skin and corresponding wine.

\section{Climatic correlation}

Viticultural climate represents a very important factor in the accumulation of trans-resveratrol in grapes. The studied area is characterised by a favourable climate for grape cultivation with moderate temperatures, long sunshine, and rainfall occurring in summer. No irrigation was applied to the area during the course of this study.

Variation of the polyphenolic content in red wines is probably due to the quantity of sunlight to which the grapes were exposed during cultivation, which favours the accumulation of polyphenols (48). Because of that, climatic data were recorded using an automatic weather station (Weather Master 2000, Environdata, Warwick, Queensland, Australia), located in the SCDVV Murfatlar perimeter, and it includes daily observations on the main climate parameters: air temperature, humidity and rainfall. Daily temperatures were recorded and the values represent the average measured at three different hours, 8 am, $2 \mathrm{pm}$ and $8 \mathrm{pm}$ (during the summer schedule). The average temperatures were expressed for each harvest period. Observations on the duration of sunshine were made with a heliographic device, which records automatically the special diagrams (heliograms), signifying the 
Table 2. Viticultural climate conditions for the investigated region during ripening

\begin{tabular}{|c|c|c|c|c|c|c|c|}
\hline \multirow{2}{*}{ Year } & \multirow{2}{*}{ Period } & \multicolumn{3}{|c|}{ Temperature $/{ }^{\circ} \mathrm{C}$} & \multirow{2}{*}{$\frac{\text { Precipitation }}{\mathrm{L} / \mathrm{m}^{2}}$} & \multirow{2}{*}{$\frac{t \text { (sunshine) }}{\mathrm{h}}$} & \multirow{2}{*}{$\frac{N\left(\text { rainfall }>10 \mathrm{~L} / \mathrm{m}^{2}\right)}{\text { day }}$} \\
\hline & & Average & Minimum & Maximum & & & \\
\hline \multirow{3}{*}{2012} & veraison (July) & 28.0 & 13.1 & 38.2 & 33.2 & 341.6 & 1 (29 July) \\
\hline & intermediate (August) & 26.1 & 10.7 & 39.8 & 8.8 & 345.6 & 0 \\
\hline & ripening (September) & 20.7 & 7.8 & 36.0 & 5.6 & 288.2 & 0 \\
\hline \multirow{3}{*}{2013} & veraison (July) & 27.2 & 18.9 & 32.1 & 158.8 & 307.0 & $4(4,16,30,31$ Jul. $)$ \\
\hline & intermediate (August) & 27.3 & 18.8 & 32.6 & 52.0 & 286.5 & 3 (4, 12, 29 Aug.) \\
\hline & ripening (September) & 20.3 & 13.8 & 25.6 & 72.6 & 144.9 & $3(14,29,30$ Sept.) \\
\hline
\end{tabular}

time expressed in hours during which the sun shines each day in a month.

Climatic conditions in 2012 were more favourable for obtaining rich harvest, with high quality wines, being more warm and dry, with a greater number of sunny days, compared to 2013 (Table 2).

The amount of trans-resveratrol was significantly higher in 2012, compared with 2013, in both grape skins and the corresponding wines of all studied varieties, probably due to the climatic conditions (Table 2).

\section{Conclusions}

Trans-resveratrol in grape skins of five red varieties: Pinot Noir, Merlot, Cabernet Sauvignon, Feteasca Neagra and Mamaia grown in Dobrogea wine-producing area (Southeastern Romania), produced in two different harvest years (2012 and 2013) under the same agronomic conditions, and microclimatic for one year, showed significant differences. Based on trans-resveratrol content, each variety had a different ripening trend, and significant differences between the seven sampling dates were found for Feteasca Neagra variety, 2012 harvest, and Pinot Noir variety, 2013 harvest. The ripening influenced the trans-resveratrol content of red grape berry skins, higher amounts of trans-resveratrol being found on the last sampling day in almost each variety and both harvest years. This finding is highly important for managing winemaking process in order to obtain wines with high trans-resveratrol content.

Comparing the studied grape varieties at the moment of harvest in the two harvest years, we can observe great differences in trans-resveratrol content, except for Feteasca Neagra, Pinot Noir and Cabernet Sauvignon varieties in 2013 harvest. The amount of trans-resveratrol in the investigated red grapes was higher in 2012 than 2013, in concordance with favourable climatic conditions of 2012, confirming that climate represents a very important factor in viticulture for the accumulation of trans-resveratrol in grapes. A significant correlation between the content of trans-resveratrol in grape skin and that in the respective wine was observed.

\section{Acknowledgements}

This study was financed by the Romanian Ministry of Education and Research, the National Authority for Scientific Research, 19N/2009 NUCLEU Program, under
Project PN 09190204. The authors would like to thank the anonymous reviewers for their valuable comments and suggestions to improve the quality of the paper.

\section{References}

1. Piñeiro Z, Palma M, Barroso CG. Determination of trans-resveratrol in grapes by pressurised liquid extraction and fast high-performance liquid chromatography. J Chromatogr A. 2006;110:61-5. http://dx.doi.org/10.1016/j.chroma.2006.01.067

2. Iacopini P, Baldi M, Storchi P, Sebastiani L. Catechin, epicatechin, quercetin, rutin and resveratrol in red grape: content, in vitro antioxidant activity and interactions. J Food Compos Anal. 2008;21:589-98.

http://dx.doi.org/10.1016/j.jfca.2008.03.011

3. Zhang Y, Liu Y, Wang T, Li B, Li H, Wang Z, et al. Resveratrol, a natural ingredient of grape skin: Antiarrhythmic efficacy and ionic mechanisms. Biochem Biophys Res Commun. 2006;340:1192-9.

http://dx.doi.org/10.1016/j.bbrc.2005.12.124

4. Wang W, Tang K, Yang HR, Wen PF, Zhang P, Wang HL, et al. Distribution of resveratrol and stilbene synthase in young grape plants (Vitis vinifera L. cv. Cabernet Sauvignon) and the effect of UV-C on its accumulation. Plant Physiol Biochem. 2010;48:142-52.

http://dx.doi.org/10.1016/j.plaphy.2009.12.002

5. Gerogiannaki-Christopoulou M, Athanasopoulos P, Kyriakidis N, Gerogiannaki IA, Spanos M. trans-Resveratrol in wines from the major Greek red and white grape varieties. Food Control. 2006;17:700-6.

http://dx.doi.org/10.1016/j.foodcont.2005.04.006

6. Sun B, Ribes AM, Leandro MC, Belchior AP, Spranger MI. Stilbenes: Quantitative extraction from grape skins, contribution of grape solids to wine and variation during wine maturation. Anal Chim Acta. 2006;563:382-90.

http://dx.doi.org/10.1016/j.aca.2005.12.002

7. Obreque-Slier E, Peña-Neira A, López-Solís R, Zamora-Marín F, Ricardo-da Silva JM, Laureano O. Comparative study of the phenolic composition of seeds and skins from Carménère and Cabernet Sauvignon grape varieties (Vitis vinifera L.) during ripening. J Agric Food Chem. 2010;58:3591-9. http://pubs.acs.org/doi/full/10.1021/jf904314u

8. Giuffrè AM. HPLC-DAD detection of changes in phenol content of red berry skins during grape ripening. Eur Food Res Technol. 2013;237:555-64. http://dx.doi.org/10.1007/s00217-013-2033-7

9. Cravero MC, Bonello F, Tsolakis C, Piano F, Borsa D. Comparison between Nero d'Avola wines produced with grapes grown in Sicily and Tuscany. Ital J Food Sci. 2012;24:384-7.

10. Budić-Leto I, Lovrić T, Pezo I, Gajdoš Kljusurić J. Study of dynamics of polyphenol extraction during traditional and 
advanced maceration processes of the Babic grape variety. Food Technol Biotechnol. 2005;43:47-53.

11. Klenar I, Berović M, Wondra M. Phenolic compounds from the fermentation of cultivars Cabernet Sauvignon and Merlot from the Slovenian coastal region. Food Technol Biotechnol. 2004;42:11-17.

12. Caridi A, Cufari A, Lovino R. Influence of yeast on polyphenol composition of wine. Food Technol Biotechnol. 2004;42: 37-40.

13. Coletta A, Berto S, Crupi P, Cravero MC, Tamborra P, Antonacci $\mathrm{D}$, et al. Effect of viticulture practices on concentration of polyphenolic compounds and total antioxidant capacity of Southern Italy red wines. Food Chem. 2014;152:467-74. http://dx.doi.org/10.1016/j.foodchem.2013.11.142

14. Feijóo O, Moreno A, Falqué E. Content of trans- and cis-resveratrol in Galician white and red wines. J Food Compos Anal. 2008;21:608-13. http://dx.doi.org/10.1016/j.jfca.2008.06.002

15. Cvejic JM, Djekic SV, Petrovic AV, Atanackovic MT, Jovic SM, Brceski ID, et al. Determination of trans- and cis-resveratrol in Serbian commercial wines. J Chromatogr Sci. 2010;48:229-34 doi:10.1093/chromsci/48.3.229

16. Geana EI, Ionete RE, Tudorache A, Pasa R, Postolache E, Ranca A. Phenolic contents of Romanian wines with different geographical origins. Asian J Chem. 2011;23:5197-201.

17. Geana EI, Costinel D, Marinescu A, Ionete RE, Bala C. Characterization of wines by trans-resveratrol concentration: A case study of Romanian varieties. Anal Lett. 2014;47:1737-46. http://dx.doi.org/10.1080/00032719.2014.883521

18. Geana EI, Marinescu A, Iordache AM, Sandru C, Ionete RE, Bala C. Differentiation of Romanian wines on geographical origin and wine variety by elemental composition and phenolic components. Food Anal Methods. 2014;7:2064-74. http://dx.doi.org/10.1007/s12161-014-9846-2

19. Sagratini G, Maggi F, Caprioli G, Cristalli G, Ricciutelli M, Torregiani E, et al. Comparative study of aroma profile and phenolic content of Montepulciano monovarietal red wines from the Marches and Abruzzo regions of Italy using HS-SPME-GC-MS and HPLC-MS. Food Chem. 2012;132:1592-9. http://dx.doi.org/10.1016/j.foodchem.2011.11.108

20. Ballus CA, Meinhart AD, de Oliveira RG, Godoy HT. Optimization of capillary zone electrophoresis separation and online preconcentration of 16 phenolic compounds from wines produced in South America. Food Res Int. 2012;45:136-44. http://dx.doi.org/10.1016/j.foodres.2011.09.029

21. Porgal E, Büyüktuncel E. Determination of phenolic composition and antioxidant capacity of native red wines by high performance liquid chromatography and spectrophotometric methods. Food Res Int. 2012;45:145-54. http://dx.doi.org/10.1016/j.foodres.2011.10.025

22. Šeruga M, Novak I, Jakobek L. Determination of polyphenols content and antioxidant activity of some red wines by differential pulse voltammetry, HPLC and spectrophotometric methods. Food Chem. 2011;124:1208-16. http://dx.doi.org/10.1016/j.foodchem.2010.07.047

23. Ginjom I, D'Arcy B, Caffin N, Gidley M. Phenolic compound profiles in selected Queensland red wines at all stages of the wine-making process. Food Chem. 2011;125:823-34. http://dx.doi.org/10.1016/j.foodchem.2010.08.062

24. Bravo MN, Feliciano R, Silva S, Coelho AV, Vilas Boas L, Bronze MR. Analysis of trans-resveratrol: Comparison of methods and contents in Muscatel fortified wines from Setúbal region in Portugal. J Food Compos Anal. 2008;21:634-43. http://dx.doi.org/10.1016/j.jfca.2008.04.007

25. Fernández-Mar MI, Mateos R, García-Parrilla MC, Puertas B, Cantos-Villar E. Bioactive compounds in wine: resveratrol hydroxytyrosol and melatonin: a review. Food Chem. 2012;
130:797-813.

http://dx.doi.org/10.1016/j.foodchem.2011.08.023

26. La Torre GL, Fortunato Vilasi MS, Pellicano T, Dugo G. Direct determination of phenolic compounds in Sicilian wines by liquid chromatography with PDA and MS detection. Food Chem. 2006;94:640-50.

http://dx.doi.org/10.1016/j.foodchem.2005.02.007

27. Gürbüz O, Göçmen D, Dagdelen F, Gürsoy M, Aydin S, Şahin $\dot{\mathrm{I}}$, et al. Determination of flavan-3-ols and trans-resveratrol in grapes and wine using HPLC with fluorescence detection. Food Chem. 2007;100:518-25. http://dx.doi.org/10.1016/j.foodchem.2005.10.008

28. Ignat I, Volf I, Popa VI. A critical review of methods for characterisation of polyphenolic compounds in fruits and vegetables. Food Chem. 2011;126:1821-35.

http://dx.doi.org/10.1016/j.foodchem.2010.12.026

29. Lorrain B, Ky I, Pechamat L, Teissedre PL. Evolution of analysis of polyhenols from grapes, wines, and extracts. Molecules. 2013;18:1076-100. http://dx.doi.org/10.3390/molecules18011076

30. Cho YJ, Hong JY, Chun HS, Lee SK, Min HY. Ultrasonication-assisted extraction of resveratrol from grapes. J Food Eng. 2006;77:725-30.

http://dx.doi.org/10.1016/j.jfoodeng.2005.06.076

31. Careri M, Corradini C, Elviri L, Nicoletti I, Zagnoni I. Direct HPLC analysis of quercetin and trans-resveratrol in red wine, grape, and winemaking byproducts. J Agric Food Chem. 2003;51:5226-31. http://pubs.acs.org/doi/pdfplus/10.1021/jf034149g

32. Vatai T, Škerget $M, K n e z ~ Z ̌$. Extraction of phenolic compounds from elder berry and different grape marc varieties using organic solvents and/or supercritical carbon dioxide. J Food Eng. 2009;90:246-54. http://dx.doi.org/10.1016/j.jfoodeng.2008.06.028

33. Ratnasooriya CC, Rupasinghe HPV. Extraction of phenolic compounds from grapes and their pomace using $\beta$-cyclodextrin. Food Chem. 2012;134:625-31.

http://dx.doi.org/10.1016/j.foodchem.2012.02.014

34. Piscopo A, Romeo FV, Petrovicova B, Poiana M. Effect of the harvest time on kernel quality of several almond varieties (Prunus dulcis (Mill.) D.A. Webb). Sci Hortic. 2010;125:41-6. http://dx.doi.org/10.1016/j.scienta.2010.02.015

35. Wassner D, Larran A, Rondanini D. Evaluation of Jatropha macrocarpa as an oil crop for biodiesel production in arid lands of the Dry Chaco, Argentina. J Arid Environ. 2012;77: 153-6. http://dx.doi.org/10.1016/j.jaridenv.2011.08.011

36. Giuffrè AM, Louadj L. Influence of crop season and cultivar on sterol composition of monovarietal olive oils in Reggio Calabria (Italy). Czech J Food Sci. 2013;31:256-63.

37. Giuffrè AM. Influence of cultivar and harvest year on triglyceride composition of olive oils produced in Calabria (Southern Italy). Eur J Lipid Sci Technol. 2013;115:928-34. http://dx.doi.org/10.1002/ejlt.201200390

38. Giuffrè AM. Evolution of fatty alcohols in olive oils produced in Calabria (Southern Italy) during fruit ripening. J Oleo Sci. 2014;63:486-96. http://dx.doi.org/10.5650/jos.ess13212

39. Giuffrè AM. Influence of harvest year and cultivar on wax composition of olive oils. Eur J Lipid Sci Technol. 2013;115: 549-55. http://dx.doi.org/10.1002/ejlt.201200235

40. Giuffrè AM. High performance liquid chromatography-diode array detector (HPLC-DAD) detection of trans-resveratrol: evolution during ripening in grape berry skins. Afr J Agric Res. 2013;8:224-9. http://dx.doi.org/10.5897/AJAR11.2257 
41. Artem V, Geana EI, Antoce AO. Study of phenolic compounds in red grapes and wines from Murfatlar wine center. Ovidius Univ Ann Chem. 2014;25:47-52.

http://dx.doi.org/10.2478/auoc-2014-0009

42. Commission Regulation (EC) no 2729/2000 laying down detailed implementing rules on controls in the wine sector. Off J Eur Commun. 2000; L316:16-29.

43. Tardea C. Wine chemistry and analysis. Iasi, Romania: Ion Ionescu de la Brad Press; 2007.

44. Geana EI, Iordache AM, Ionete RE. Analysis and quantification of trans-resveratrol in wine from Muntenia and Oltenia region, Romania, Proceedings of the 4th International Symposium 'New Researches in Biotechnology', Bucharest, Romania. 2011:176-83.

45. Navarro S, León M, Roca-Pérez L, Boluda R, García-Ferriz L, Pérez-Bermúdez P, et al. Characterisation of Bobal and Crujidera grape cultivars, in comparison with Tempranillo and Cabernet Sauvignon: Evolution of leaf macronutrients and berry composition during grape ripening. Food Chem. 2008; 108:182-90. http://dx.doi.org/10.1016/j.foodchem.2007.10.060

46. Caia L, Koziel JA, Dharmadhikari M, van Leeuwen J. Rapid determination of trans-resveratrol in red wine by solid-phase microextraction with on-fiber derivatization and multidimensional gas chromatography-mass spectrometry. J Chromatogr A. 2009;1216:281-7.

http://dx.doi.org/10.1016/j.chroma.2008.11.050

47. Mark L, Nikfardjam MS, Avar P, Ohmacht R. A validated HPLC method for the quantitative analysis of trans-resveratrol and trans-piceid in Hungarian wines. J Chromatogr Sci. 2005;43:445-9. doi:10.1093/chromsci/43.9.445

48. Rastija V, Srečnik G. Polyphenolic composition of Croatian wines with different geographical origins. Food Chem. 2009; 115:54-60. http://dx.doi.org/10.1016/j.foodchem.2008.11.071 